\title{
Decolorization of methylene blue in layered manganese oxide suspension with $\mathrm{H}_{2} \mathrm{O}_{2}$
}

\author{
Lili Zhang, Yulun Nie*, Chun $\mathrm{Hu}^{*}$, Xuexiang $\mathrm{Hu}$ \\ State Key Laboratory of Environmental Aquatic Chemistry, Research Center for Eco-Environmental Sciences, Chinese Academy of Sciences, Beijing 100085, China
}

\section{A R T I C L E I N F O}

\section{Article history:}

Received 30 September 2010

Received in revised form 31 March 2011

Accepted 31 March 2011

Available online 7 April 2011

\section{Keywords:}

Na-OL-1

Multivalent manganese oxides

Methylene blue

Decolorization

\begin{abstract}
A B S T R A C T
Layered birnessite-type manganese oxides (Na-OL-1) were prepared via a redox reaction involving $\mathrm{MnO}_{4}{ }^{-}$and $\mathrm{Mn}^{2+}$ under markedly alkaline conditions. According to the XRD analysis, the resulting material exhibited a well-crystallized octahedral layer (OL) structure with several different phases, including $\beta-\mathrm{MnOOH}, \alpha-\mathrm{MnOOH}$ and $\gamma-\mathrm{Mn}_{3} \mathrm{O}_{4}$. The catalyst was highly effective for the decolorization and degradation of methylene blue (MB) in the presence of $\mathrm{H}_{2} \mathrm{O}_{2}$ at neutral pH. The tested $\mathrm{MB}$ was completely decolorized in Na-OL-1 suspension by the fraction dosing of $\mathrm{H}_{2} \mathrm{O}_{2}(556.5 \mathrm{mM}$ at the beginning and then $183.8 \mathrm{mM}$ at $40 \mathrm{~min}$ ). Based on the studies of electron spin resonance and the effect of radical scavengers, the ${ }^{1} \mathrm{O}_{2}$ and $\mathrm{O}_{2}{ }^{--}$were the main reactive oxygen species (ROS) in the reaction. It was found that both oxygen and ROS were generated from the decomposition of $\mathrm{H}_{2} \mathrm{O}_{2}$ in Na-OL-1 suspension, wherein the decomposition pathways were proposed. The generation of $\mathrm{H}_{2} \mathrm{O}_{2}$ in Na-OL-1 suspension at air atmosphere indicated that the existence of multivalent manganese oxides greatly enhanced the interfacial electron transfer, leading to the high activity of Na-OL-1.
\end{abstract}

(C) 2011 Published by Elsevier B.V.

\section{Introduction}

Methylene blue (MB), one of the colored organic compounds, is the most commonly used substance for dying cotton, wood and silk. However, it can result in permanent burns to the eyes of human and animals, nausea, vomiting, profuse sweating, mental confusion and methemoglobinemia [1]. Therefore, the removal of MB has attracted considerable attention in the environmental field.

Advanced oxidation technologies for wastewater treatment have attracted attention due to the generation of highly potent chemical species $\left(\bullet \mathrm{OH}, \mathrm{O}_{2}{ }^{\bullet-}\right.$, etc.). One of them is the classic Fenton process (dissolved $\mathrm{Fe}(\mathrm{II})$ and $\mathrm{H}_{2} \mathrm{O}_{2}$ ) [2], which is capable of degrading organic pollutants into harmless chemicals such as $\mathrm{CO}_{2}$ and $\mathrm{H}_{2} \mathrm{O}$. However, the application of traditional Fenton reaction is limited by the narrow working $\mathrm{pH}$ range $(<4)[3,4]$, separation and recovery of the iron species specially in industrial wastewater treatment [5]. To overcome these drawbacks, some efforts have been made to develop heterogeneous Fenton systems [6,7] and many heterogeneous Fenton-like catalysts have been reported, such as iron oxides [8-12], iron-immobilized zeolites [13], clays [14,15], and carbon materials $[16,17]$. In comparison with the traditional ion Fenton catalysts, the heterogeneous catalysts can be used over a wider $\mathrm{pH}$ range for the degradation of organic pollutants. How-

\footnotetext{
* Corresponding authors. Tel.: +86 10 62849628; fax: +86 1062923541.

E-mail addresses: huchun@rcees.ac.cn (C. Hu), ylnie@rcees.ac.cn (Y. Nie).
}

ever, the better catalytic performance is dependent on the presence of ultrasonic and/or UV light irradiation to accelerate the electron transfer at the interface of catalyst and water.

Since the electron transfer process exists in the Fenton reaction, the catalysts with accessible multiple oxidation states should have an excellent Fenton performance. Due to the various oxidation states of $\mathrm{Mn}$ element, manganese oxides $\left(\alpha-\mathrm{MnO}_{2}, \beta-\mathrm{MnO}_{2}\right.$ and $\gamma-\mathrm{MnO}_{2}$ ) have wide application in many fields $[18,19]$. Birnessitetype manganese oxide is an octahedral layer (OL) material with cations and water in the interlayer space of negatively charged layers of edge-sharing $\mathrm{MnO}_{6}$ octahedral containing mixed valence states of $\mathrm{Mn}\left(\mathrm{Mn}^{4+}, \mathrm{Mn}^{3+}, \mathrm{Mn}^{2+}\right.$ ions $)$ and oxygen vacancies [20,21]. This material has been applied for the adsorption of heavy metal cations [22], catalytic oxidation of alcohols/CO [23] and decomposition of the organic sulfur compounds [24]. More recently, OL-1 materials have been used in the electrocatalytic oxidation of styrene under voltage, $\mathrm{O}_{2}$ and $\mathrm{H}_{2} \mathrm{O}_{2}$ [25]. Moreover, it has been reported that the active radicals are generated in manganese oxide- $\mathrm{H}_{2} \mathrm{O}_{2}$ systems [26-29], such as ${ }^{\bullet} \mathrm{OH}$ in $\mathrm{Mn}_{3} \mathrm{O}_{4} / \mathrm{SBA}-15$ system [26], $\mathrm{O}_{2}{ }^{\bullet-}, \mathrm{HO}_{2}{ }^{\bullet}, \mathrm{H}$ in $\beta-\mathrm{MnO}_{2} / \mathrm{H}_{2} \mathrm{O}_{2}$ system [27], $\mathrm{O}_{2}{ }^{-}-/ \mathrm{HO}_{2}{ }^{\bullet}$ in pyrolusite- $\mathrm{H}_{2} \mathrm{O}_{2}$ system [28], and $\mathrm{O}_{2} \cdot-$ in acid birnessite- $\mathrm{H}_{2} \mathrm{O}_{2}$ system [29]. Therefore, OL-1 material should be a forceful candidate as Fenton catalyst for the effective removal of organics present in water.

The objective of this study was to investigate the Fenton-like catalytic performance of OL-1 materials for the decolorization of $\mathrm{MB}$ under natural conditions. In the present study, layered 
birnessite-type manganese oxides (Na-OL-1) were prepared via a redox reaction involving $\mathrm{MnO}_{4}{ }^{-}$and $\mathrm{Mn}^{2+}$ under markedly alkaline conditions. The resulting material was found to be highly effective for the decolorization of $\mathrm{MB}$ with $\mathrm{H}_{2} \mathrm{O}_{2}$ as oxidant at neutral $\mathrm{pH}$. The Fenton-like reaction mechanism was also investigated by determining the reactive oxygen species in $\mathrm{Na}-\mathrm{OL}-1 / \mathrm{H}_{2} \mathrm{O}_{2}$ system.

\section{Experimental}

\subsection{Reagents}

Methylene blue $(\mathrm{MB})$, potassium permanganate $\left(\mathrm{KMnO}_{4}\right)$ and potassium bromide ( $\mathrm{KBr}$ ) were obtained from Beijing Yili Company. Sodium hydroxide $(\mathrm{NaOH})$, manganese(II) acetate tetrahydrate $\left(\mathrm{Mn}(\mathrm{Ac})_{2} \cdot 4 \mathrm{H}_{2} \mathrm{O}\right), \mathrm{H}_{2} \mathrm{O}_{2}(30 \%, \mathrm{w} / \mathrm{w})$, sodium azide $\left(\mathrm{NaN}_{3}\right)$ and $p$ benzoquinone were purchased from Sinopharm Chemical Reagent Co. Ltd. The reagent, $t$-butanol was provided by Tianjin Fuchen Company. 5,5-Dimethyl-1-pyrroline-N-oxide (DMPO) was supplied by Sigma. All chemicals were at least analytical grade. Deionized water was used throughout this study.

\subsection{Preparation of $\mathrm{Na}-\mathrm{OL}-1$}

The catalyst was prepared via a preciously reported redox process [30]. In a typical procedure, a solution of $\mathrm{Mn}(\mathrm{Ac})_{2} \cdot 4 \mathrm{H}_{2} \mathrm{O}$ was added slowly to a $\mathrm{NaOH}$ solution under vigorous magnetic stirring. A pink $\mathrm{Mn}(\mathrm{OH})_{2}$ gel was then formed. A $\mathrm{KMnO}_{4}$ solution $\left(\mathrm{MnO}_{4}{ }^{-} / \mathrm{Mn}^{2+}=0.335\right)$ was added slowly to the above gel under continuous stirring. Subsequently, a brownish black suspension or gel was generated at $\left[\mathrm{OH}^{-}\right]=2.83 \mathrm{M}$. The mixtures were kept at $35^{\circ} \mathrm{C}$ in ovens for aging 4 days. After being filtered, washed and air-dried at $60^{\circ} \mathrm{C}$, a brownish-black product denoted as Na-OL-1 was finally obtained.

\subsection{Characterization}

The powder X-ray diffraction (XRD) pattern of the catalyst was recorded on a Scintag-XDS-2000 diffractometer with $\mathrm{Cu} \mathrm{K} \alpha$ radiation $(\lambda=1.540598 \AA)$. The generator voltage and tube current used were $40 \mathrm{kV}$ and $40 \mathrm{~mA}$, respectively. The $2 \theta$ ranged from $10^{\circ}$ to $90^{\circ}$. The crystalline size was estimated via the Scherer equation. Reactive oxygen species were detected by electron spin resonance (ESR) spectroscopy using DMPO as a spin trap agent. The reaction mixture for ESR measurement contained $1.0 \mathrm{~mL}$ ultra-pure water, $0.5 \mathrm{~mL} \mathrm{H}_{2} \mathrm{O}_{2}(30 \%, \mathrm{w} / \mathrm{w})$ and $10 \mathrm{mg} \mathrm{Na}-\mathrm{OL}-1$. Immediately, $100 \mu \mathrm{L}$ of the above suspension were mixed with $20 \mu \mathrm{L} 0.2 \mathrm{M}$ DMPO. The ESR spectra were obtained using a Bruker model ESP 300E electron paramagnetic resonance spectrometer (center field: 3480.00 G; microwave frequency: $9.79 \mathrm{GHz}$; and power: $5.05 \mathrm{~mW}$ ).

\subsection{Procedures and analysis}

The catalytic reaction was carried out at ambient atmosphere. In a typical experiment, $10 \mathrm{mg} \mathrm{Na}-\mathrm{OL}-1$ powders were dispersed in $50 \mathrm{~mL} \mathrm{MB}$ solution $\left(30 \mathrm{mg} \mathrm{L}^{-1}\right)$. The solution $\mathrm{pH}$ (ca. 7.60) was nearly unchanged during the catalytic reaction. Prior to the addition of $\mathrm{H}_{2} \mathrm{O}_{2}$, the suspensions were magnetically stirred for about 20 min to establish the adsorption/desorption equilibrium between the dye and catalyst. Then, a certain amount of $\mathrm{H}_{2} \mathrm{O}_{2}$ was added to the above suspensions under continuous magnetic stirring. At given time intervals, $2 \mathrm{~mL}$ aliquots were collected and immediately centrifuged to remove the catalyst for analysis. The supernatant was analyzed by recording variations at the wavelength of maximum absorption using a Hitachi UV-3010 UV-visible spectrophotometer. The $\mathrm{SO}_{4}{ }^{2-}$ and $\mathrm{NO}_{3}{ }^{-}$ions were determined by 861 advanced compact ion chromatography (Metrohm, Switzerland).

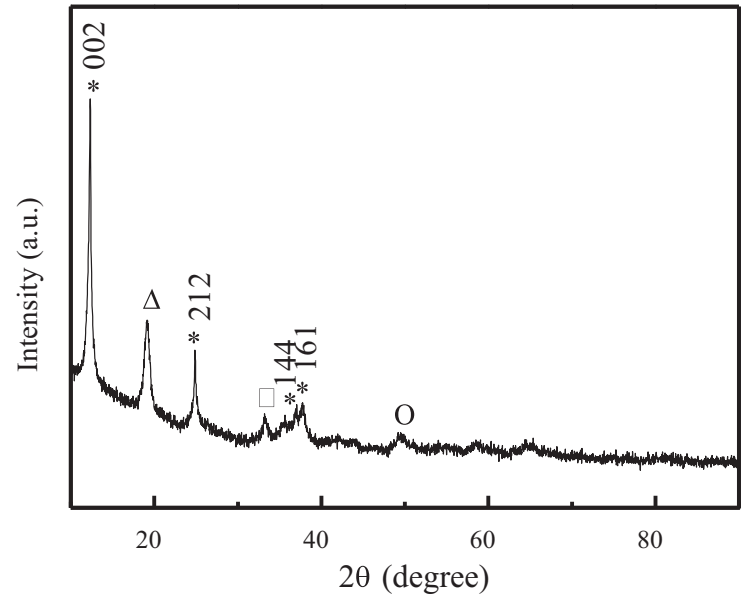

Fig. 1. XRD pattern of the synthesized catalyst: $\left(^{*}\right)$ Na-Birnessite; $(\triangle)$ Feitknechtite; $(\square)$ Groutite; ( $\bigcirc)$ Hausmannite.

All of the above experiments were repeated three times and each data represented the average of the triplicates with a standard deviation less than $5 \%$. In addition, the difference of the MB decolorization efficiency in $\mathrm{Na}-\mathrm{OL}-1 / \mathrm{H}_{2} \mathrm{O}_{2}$ suspension with and without $t$-butanol was also measured by performing ANOVA. The significance level of the statistical hypothesis test was $\alpha=0.05$.

Samples for FT-IR analysis were prepared by the following procedure. The suspensions before and after reaction were filtered to remove Na-OL-1 particles. The filtrates were evaporated by freezedrying method. For FT-IR measurement, the dry residues were supported on $\mathrm{KBr}$ pellets at a fixed weight ratio (0.7\%), respectively. The infrared spectra were recorded on Bruker Tensor 27 FTIR Spectrophotometer.

$\mathrm{H}_{2} \mathrm{O}_{2}(30 \%, w / w)$ concentration was determined by the titration of $\mathrm{KMnO}_{4}$.

\section{Results and discussion}

\subsection{Characterization of $\mathrm{Na}-\mathrm{OL}-1$}

The XRD pattern of as-prepared Na-OL-1 was shown in Fig. 1. The characteristic peaks at 002, 212, 144 and 161 marked with asterisks $\left({ }^{*}\right)$ were assigned to a well-crystallized Na-Birnessite (JCPDS 23-1046) [31]. Moreover, the peak at 002, representing the Mn-Mn distance from adjacent layers, was especially significant. The peaks at $2 \theta$ of $19.5^{\circ}(\triangle), 33.4^{\circ}(\square)$, and $49.5^{\circ}(\bigcirc)$ should be attributed to Feitknechtite $\beta-\mathrm{MnOOH}$ phase (JCPDS 18-0804) [32], Groutite $\alpha-\mathrm{MnOOH}$ phase (JCPDS 24-0713) [33], and Hausmannite $\gamma-\mathrm{Mn}_{3} \mathrm{O}_{4}$ phase (JCPDS 24-0734) [34], respectively. The results indicated that $\mathrm{Mn}$ element with multiple oxidation states $\left(\mathrm{Mn}^{4+}\right.$, $\mathrm{Mn}^{3+}$ and $\mathrm{Mn}^{2+}$ ) existed in Na-OL-1. Furthermore, the average size of the catalyst was $17.7 \mathrm{~nm}$ based on the calculation with Scherer equation. All the results above indicated that Na-OL-1 with mixed valences and nanostructure was successfully prepared.

\subsection{Catalytic performance of $\mathrm{Na}-\mathrm{OL}-1$}

The Fenton catalytic activity of Na-OL- 1 was evaluated by the oxidation of $\mathrm{MB}$ with $\mathrm{H}_{2} \mathrm{O}_{2}$ in aqueous solution. The time profiles of $\mathrm{MB}$ decolorization under various reaction conditions were displayed in Fig. 2. Neither as-prepared Na-OL-1 nor $\mathrm{H}_{2} \mathrm{O}_{2}$ alone showed significant activity for $\mathrm{MB}$ decolorization for $60 \mathrm{~min}$. In contrast, remarkable $\mathrm{MB}$ decolorization occurred in $\mathrm{Na}-\mathrm{OL}-1 / \mathrm{H}_{2} \mathrm{O}_{2}$ suspension and about $90 \%$ of $\mathrm{MB}$ was decolorized within $20 \mathrm{~min}$ at neutral $\mathrm{pH}$. Moreover, the major absorption peak of MB at $664 \mathrm{~nm}$ 


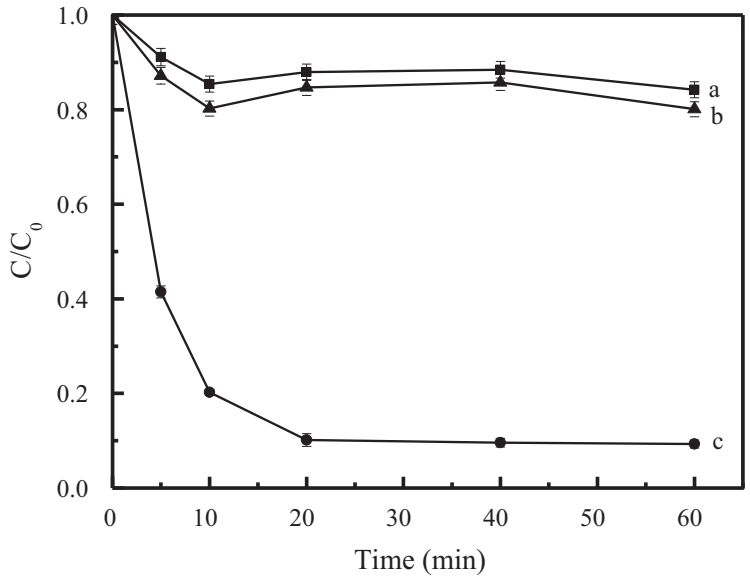

Fig. 2. Decolorization of $M B\left(30 \mathrm{mg} \mathrm{L}^{-1}\right)$ under different conditions: (a) Na-OL-1 $\left(0.2 \mathrm{~g} \mathrm{~L}^{-1}\right)$; (b) $\mathrm{H}_{2} \mathrm{O}_{2}(556.5 \mathrm{mM})$; (c) Na-OL-1 $+\mathrm{H}_{2} \mathrm{O}_{2}$. Error bars represent the standard error of the mean for three replicates.

decreased rapidly with the reaction time (Fig. S1). The results indicated that the characteristic structure of MB was destroyed [19] and the higher reactive activity came from the interaction between Na-OL-1 and $\mathrm{H}_{2} \mathrm{O}_{2}$. As shown in Fig. 3, with the $\mathrm{H}_{2} \mathrm{O}_{2}$ concentration increasing from 0 to $919.8 \mathrm{mM}$, the decolorization rate of MB increased and reached to a stable value even when the $\mathrm{H}_{2} \mathrm{O}_{2}$ concentration was more than $556.5 \mathrm{mM}$. The results indicated that there was a critical $\mathrm{H}_{2} \mathrm{O}_{2}$ dosage and the decolorization rate would not increase when a concentration higher than the critical concentration was used because of the scavenging effect of $\mathrm{H}_{2} \mathrm{O}_{2}$ [35]. The $\mathrm{H}_{2} \mathrm{O}_{2}$ concentration was thereby an important factor for MB decolorization in Na-OL-1 suspension. However, in all the experiments, the complete decolorization of MB was not observed. Oppositely, the decolorization of $\mathrm{MB}$ from $88.6 \%$ to $98 \%$ occurred when an additional $183.8 \mathrm{mM} \mathrm{H}_{2} \mathrm{O}_{2}$ was added at $40 \mathrm{~min}$ after $556.5 \mathrm{mM}$ $\mathrm{H}_{2} \mathrm{O}_{2}$ being completely decomposed (curve e). Furthermore, Fig. 4 showed the decomposition of $\mathrm{H}_{2} \mathrm{O}_{2}$ in Na-OL- $1 / \mathrm{H}_{2} \mathrm{O}_{2}$ suspension during the $\mathrm{MB}$ decolorization process. Clearly, $\mathrm{H}_{2} \mathrm{O}_{2}$ was quickly and completely decomposed within $20 \mathrm{~min}$, leading to the $\mathrm{MB}$ decolorization stopping in the latter reaction time.

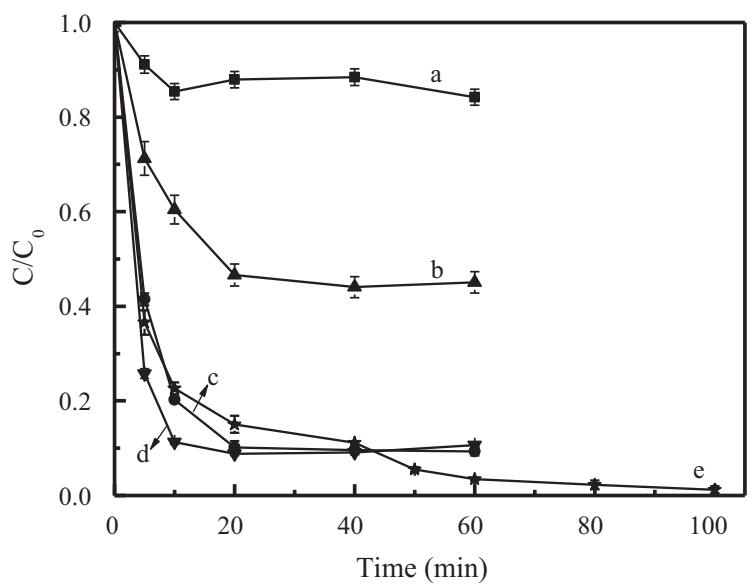

Fig. 3. Effect of initial concentration of $\mathrm{H}_{2} \mathrm{O}_{2}$ on decolorization of $\mathrm{MB}\left(30 \mathrm{mg} \mathrm{L}^{-1}\right)$ in Na-OL-1 (0.2 $\left.\mathrm{g} \mathrm{L}^{-1}\right)$ suspensions: (a) $0 \mathrm{mM}$; (b) $183.8 \mathrm{mM}$; (c) $556.5 \mathrm{mM}$; (d) $919.8 \mathrm{mM}$; (e) $556.5 \mathrm{mM}$ in the beginning and then $183.8 \mathrm{mM}$ at $40 \mathrm{~min}$. Error bars represent the standard error of the mean for three replicates.

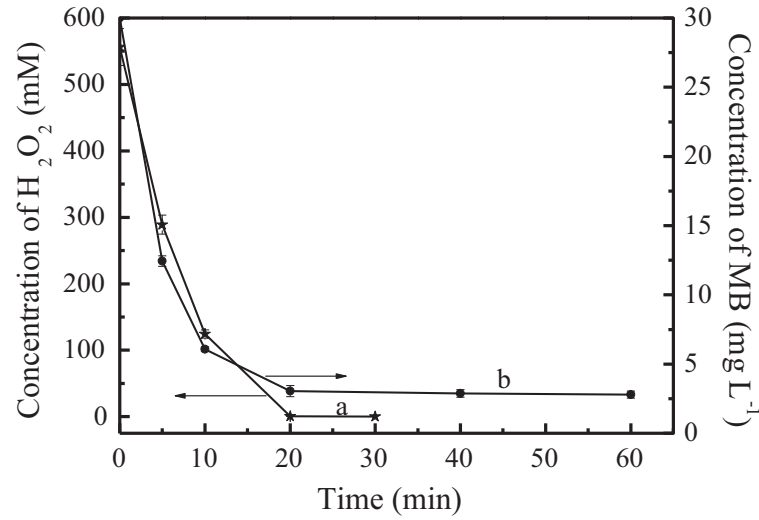

Fig. 4. Changes of the $\mathrm{H}_{2} \mathrm{O}_{2}$ (a) and $\mathrm{MB}\left(30 \mathrm{mg} \mathrm{L}^{-1}\right)$ (b) concentration in Na-OL-1 $\left(0.2 \mathrm{~g} \mathrm{~L}^{-1}\right)$ suspensions with $\mathrm{H}_{2} \mathrm{O}_{2}(556.5 \mathrm{mM})$. Error bars represent the standard error of the mean for three replicates.

\subsection{Degradation characteristics of $M B$}

Fig. 5 showed the FT-IR spectra changes of MB in Na-OL- $1 / \mathrm{H}_{2} \mathrm{O}_{2}$ suspension with reaction time increasing. In curve a, the peaks at 1601 and $1396 \mathrm{~cm}^{-1}$ were assigned to $\mathrm{C}=\mathrm{N}$ and $\mathrm{C}-\mathrm{N}$ bond in the heterocycle of $\mathrm{MB}$, respectively [36], while the peaks at 1356 and $1337 \mathrm{~cm}^{-1}$ were attributed to the $\mathrm{C}-\mathrm{N}$ bond connected with benzene ring and $\mathrm{N}-\mathrm{CH}_{3}$ bond $[37,38]$. As shown in curve $\mathrm{b}$, these characteristic peaks disappeared after reaction for $60 \mathrm{~min}$. Meanwhile, the new peaks at 1633 and $1382 \mathrm{~cm}^{-1}$ attributed to the stretching vibrations of $\mathrm{N}=\mathrm{O}$ bond, $\mathrm{N}-\mathrm{O}$ bond and $\mathrm{N}-\mathrm{H}$ bond $[39,40]$ appeared. And the peaks at 1178 and $1142 \mathrm{~cm}^{-1}$ corresponded to $\mathrm{C}=\mathrm{S}$ and $\mathrm{C}-\mathrm{S}$ vibrations shifted to 1150 and $1118 \mathrm{~cm}^{-1}$, respectively. The results indicated that the structure of $\mathrm{MB}$ had been destroyed. Moreover, the above peak intensities continued decreasing and even disappeared after reaction for $120 \mathrm{~min}$ when the other part of $183.8 \mathrm{mM} \mathrm{H}_{2} \mathrm{O}_{2}$ was added at 40 min after $556.5 \mathrm{mM} \mathrm{H}_{2} \mathrm{O}_{2}$ being completely decomposed. The results implied the disappearance of the parental MB structure and the generation of its primary aromatic breakdown products and inorganic species.

In addition, the production of $\mathrm{SO}_{4}{ }^{2-}$ and $\mathrm{NO}_{3}{ }^{-}$during the $\mathrm{MB}$ decolorization process in $\mathrm{Na}-\mathrm{OL}-1 / \mathrm{H}_{2} \mathrm{O}_{2}$ suspension at 60 min was

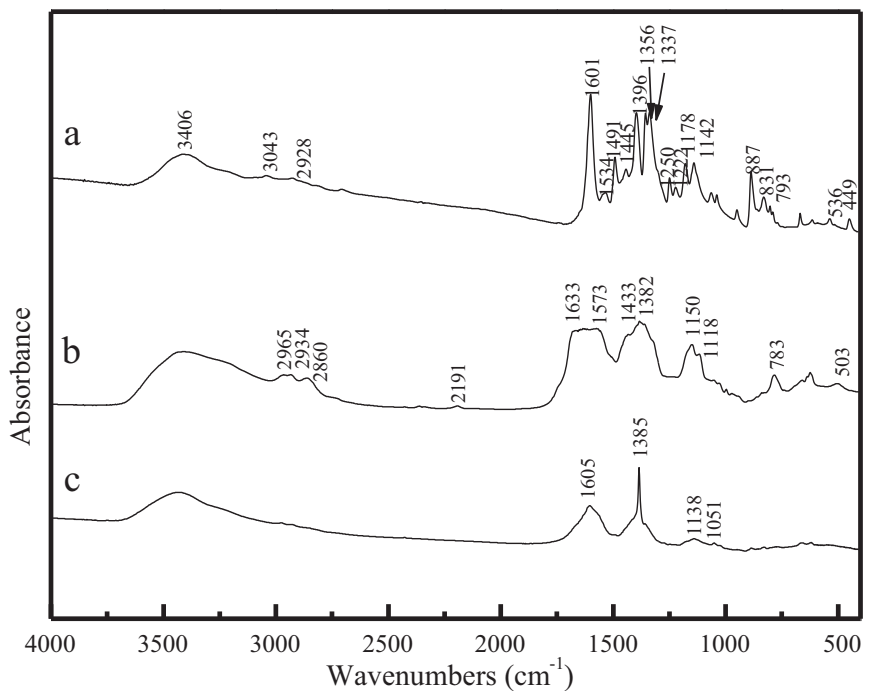

Fig. 5. Changes of FT-IR spectra during the degradation of $\mathrm{MB}\left(30 \mathrm{mg} \mathrm{L}^{-1}\right)$ in $\mathrm{Na}$ OL-1 $\left(0.2 \mathrm{~g} \mathrm{~L}^{-1}\right)$ suspensions with $\mathrm{H}_{2} \mathrm{O}_{2}$ : (a) $0 \mathrm{~min}$; (b) after 60 min reaction with $556.5 \mathrm{mM} \mathrm{H}_{2} \mathrm{O}_{2}$ added; (c) after $120 \mathrm{~min}$ reaction with first $556.5 \mathrm{mM}$ and at $40 \mathrm{~min}$ $183.8 \mathrm{mM} \mathrm{H}_{2} \mathrm{O}_{2}$ added. 


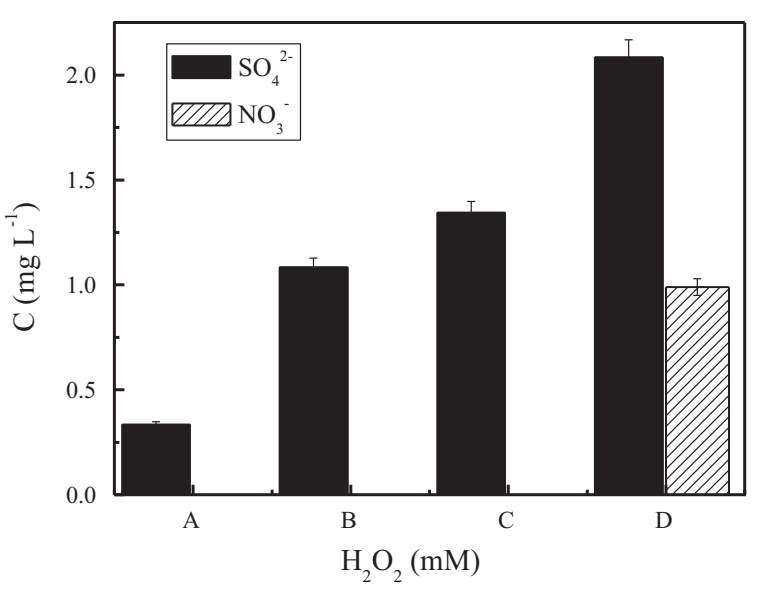

Fig. 6. The production of $\mathrm{SO}_{4}{ }^{2-}$ and $\mathrm{NO}_{3}{ }^{-}$ions from $\mathrm{MB}\left(30 \mathrm{mg} \mathrm{L}^{-1}\right)$ degradation at reaction time $60 \mathrm{~min}$ in suspensions with Na-OL-1 $\left(0.2 \mathrm{~g} \mathrm{~L}^{-1}\right)$ and different concentrations of $\mathrm{H}_{2} \mathrm{O}_{2}$ : (A) $183.8 \mathrm{mM}$; (B) $556.5 \mathrm{mM}$; (C) $919.8 \mathrm{mM}$; (D) first dosing $556.5 \mathrm{mM}$, then $183.8 \mathrm{mM}$ at $40 \mathrm{~min}$. Error bars represent the standard error of the mean for three replicates.

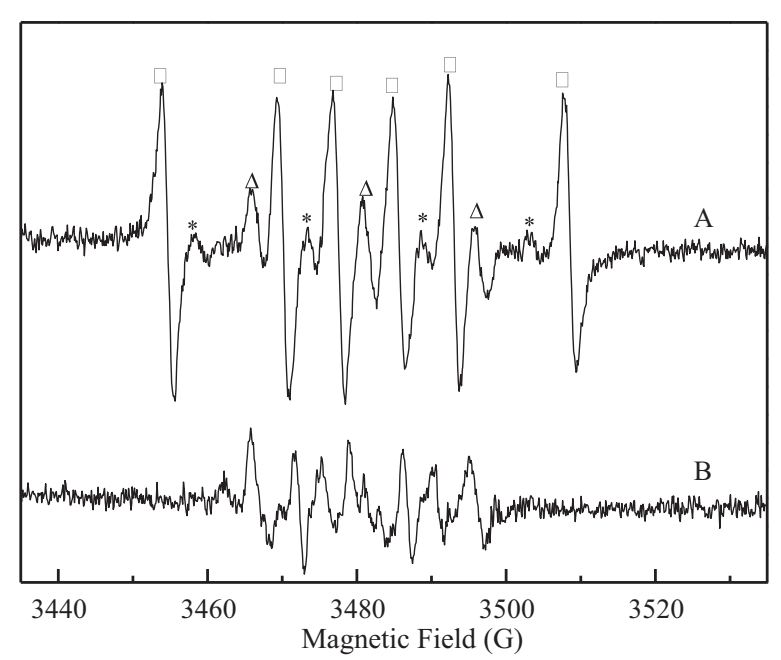

Fig. 7. DMPO spin trapping ESR spectra recorded in the dark at ambient temperature in Na-OL-1 suspensions (A) with and (B) without $\mathrm{H}_{2} \mathrm{O}_{2}$. ROS signals in the spectrum $(\mathrm{A}):\left({ }^{*}\right) \bullet \mathrm{OH},(\triangle){ }^{1} \mathrm{O}_{2},(\square) \mathrm{O}_{2}{ }^{\bullet-}$.

also detected by ion chromatography. As shown in Fig. 6, the $\mathrm{SO}_{4}{ }^{2-}$ concentration increased with the increase of $\mathrm{H}_{2} \mathrm{O}_{2}$ dosage. About $27 \%$ of the total sulfur content was converted into $\mathrm{SO}_{4}{ }^{2-}$ ions when $183.8 \mathrm{mM} \mathrm{H}_{2} \mathrm{O}_{2}$ was added at $40 \mathrm{~min}$ after $556.5 \mathrm{mM} \mathrm{H}_{2} \mathrm{O}_{2}$ being completely decomposed. Under the same conditions, about $1 \mathrm{mg} \mathrm{L}^{-1} \mathrm{NO}_{3}{ }^{-}$was generated from about $7 \%$ of the total nitrogen content. The results indicated that $\mathrm{MB}$ could be completely decolorized and partly degraded in $\mathrm{Na}-\mathrm{OL}-1 / \mathrm{H}_{2} \mathrm{O}_{2}$ suspension.

\subsection{Reaction mechanism}

To ascertain the possible reaction mechanism, DMPO spin-trap ESR was performed to detect the reactive oxygen species (ROS) involved in the Na-OL- $1 / \mathrm{H}_{2} \mathrm{O}_{2}$ system. As shown in Fig. 7, three characteristic peaks of DMPO- ${ }^{1} \mathrm{O}_{2}$ adduct, six characteristic peaks of DMPO- $\mathrm{O}_{2}{ }^{\bullet-}$ adduct, and four characteristic peaks of DMPO- $\bullet \mathrm{OH}$ adduct were observed in Na-OL-1 suspension with $\mathrm{H}_{2} \mathrm{O}_{2}$, while no significant signals attributed to ROS were observed in Na-OL-1 suspension. The evidence indicated that ${ }^{1} \mathrm{O}_{2}, \mathrm{O}_{2}{ }^{\bullet-}$ and $\bullet \mathrm{OH}$ radicals were generated in Na-OL-1 suspension with $\mathrm{H}_{2} \mathrm{O}_{2}$. However, Furman et al. [29] found that ${ }^{\bullet} \mathrm{OH}$ was not formed in a birnessite- $\mathrm{H}_{2} \mathrm{O}_{2}$

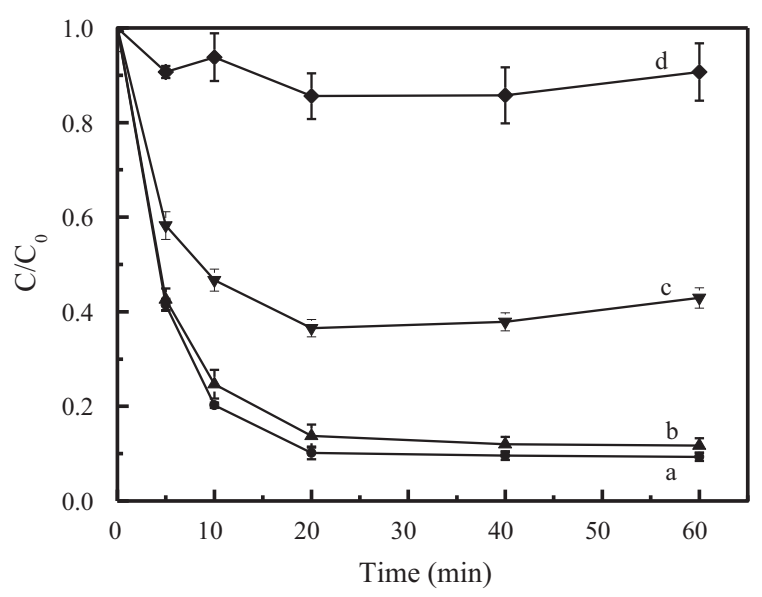

Fig. 8. Decolorization of $\mathrm{MB}\left(30 \mathrm{mg} \mathrm{L}^{-1}\right)$ in the presence of Na-OL-1 suspensions $\left(0.2 \mathrm{~g} \mathrm{~L}^{-1}\right)$ and $\mathrm{H}_{2} \mathrm{O}_{2}(556.5 \mathrm{mM}$ ) with (a) no scavenger added, (b) $10 \mathrm{mM}$ t-butanol, (c) $100 \mathrm{mM}$-benzoquinone, (d) $100 \mathrm{mM} \mathrm{NaN}_{3}$. Error bars represent the standard error of the mean for three replicates.

system, and suggested that the $\bullet \mathrm{OH}$ adduct observed in the system was actually the decomposition product of superoxide adducts. Therefore, to further verify the existence and roles of these ROS in $\mathrm{Na}-\mathrm{OL}-1 / \mathrm{H}_{2} \mathrm{O}_{2}$ suspension, the effects of various radical scavengers on the rate of $\mathrm{MB}$ decolorization were investigated. Sodium azide, $p$-benzoquinone and $t$-butanol were selected as ${ }^{1} \mathrm{O}_{2}, \mathrm{O}_{2}{ }^{\bullet-}$ and $\bullet{ }^{\bullet} \mathrm{OH}$ radical scavengers, respectively [41,42]. As shown in Fig. 8, the decolorization of MB was almost completely depressed in the presence of sodium azide and only $10 \%$ of MB was decolorized within $60 \mathrm{~min}$, while the addition of $p$-benzoquinone also significantly inhibited the decolorization of MB. Although there was no significant difference in $\mathrm{MB}$ decolorization in $\mathrm{Na}-\mathrm{OL}-1 / \mathrm{H}_{2} \mathrm{O}_{2}$ suspension with and without $t$-butanol, $t$-butanol had a little influence on the decolorization of MB. These results confirmed that ${ }^{1} \mathrm{O}_{2}$ and $\mathrm{O}_{2}{ }^{\bullet-}$ were the main ROS in the decolorization of MB in Na-OL-1/ $\mathrm{H}_{2} \mathrm{O}_{2}$ suspension, while $\bullet^{\bullet} \mathrm{OH}$ played a little role.

As shown in Fig. 4, $\mathrm{H}_{2} \mathrm{O}_{2}$ in Na-OL-1 suspension was quickly decomposed within less than $30 \mathrm{~min}$ and a large number of bubbles were also observed. As shown in Fig. S2, the bubbles were verified to be oxygen gas by the burning of the paper slip with sparks. Moreover, the produced oxygen gas was measured quantitatively in Fig. S3. These results suggested that $\mathrm{H}_{2} \mathrm{O}_{2}$ decomposition in Na-OL-1/ $\mathrm{H}_{2} \mathrm{O}_{2}$ suspension took place by two possible reaction pathways: (1) the surface oxygen vacancies mechanism and (2) the radicalar mechanism. The same mechanism has been reported in the previous work [43]. In addition, in Na-OL-1 suspension under oxygen atmosphere, $\mathrm{H}_{2} \mathrm{O}_{2}$ was also generated and its concentration increased significantly with the addition amount of Na-OL-1 (Fig. 9), indicating that two-electron transfer occurred from NaOL-1 $\left(\mathrm{Mn}^{3+} / \mathrm{Mn}^{4+} \rightarrow \mathrm{Mn}^{2+} / \mathrm{Mn}^{3+}\right)$ to oxygen. Since dissolved oxygen was responsible for the generation of singlet oxygen [44], singlet oxygen was then most likely generated from the reaction between Na-OL-1 and the nascent oxygen, other than $\mathrm{H}_{2} \mathrm{O}_{2}$. In light of the experimental data and a review of the literature [43], both $\mathrm{H}_{2} \mathrm{O}_{2}$ decomposition pathways were proposed in the Na-OL-1 suspension.

$$
\begin{aligned}
& \mathrm{Mn}^{3+} / \mathrm{Mn}^{4+}+\mathrm{H}_{2} \mathrm{O}_{2} \rightarrow \mathrm{Mn}^{2+} / \mathrm{Mn}^{3+}+\mathrm{O}_{2} \cdot-+2 \mathrm{H}^{+} \\
& \mathrm{O}_{2}{ }^{--}+\mathrm{H}_{2} \mathrm{O} \rightarrow \cdot \mathrm{OH}+\mathrm{H}_{2} \mathrm{O}_{2} \\
& \mathrm{Mn}^{2+} / \mathrm{Mn}^{3+}+\mathrm{O}_{2} \stackrel{2 \mathrm{e}}{\longrightarrow} \mathrm{Mn}^{3+} / \mathrm{Mn}^{4+}+\mathrm{H}_{2} \mathrm{O}_{2} \\
& \mathrm{Mn}^{3+} / \mathrm{Mn}^{4+}+\mathrm{O}_{2} \rightarrow \mathrm{Mn}^{2+} / \mathrm{Mn}^{3+}+{ }^{1} \mathrm{O}_{2}
\end{aligned}
$$

Therefore, the multiple oxidation states of manganese oxides in Na-OL-1 could greatly accelerate the interfacial electron transfer 


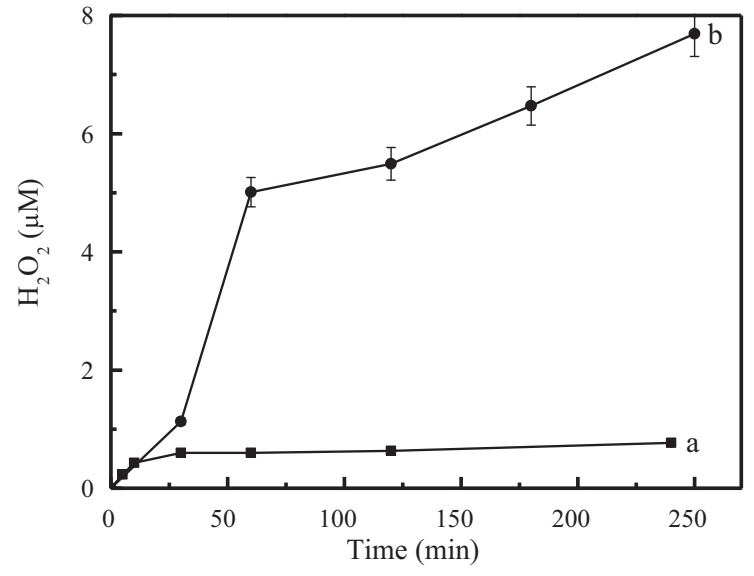

Fig. 9. Generation of $\mathrm{H}_{2} \mathrm{O}_{2}$ in Na-OL-1 suspensions of (a) $0.2 \mathrm{~g} \mathrm{~L}^{-1}$ and (b) $1.0 \mathrm{~g} \mathrm{~L}^{-1}$ in oxygen atmosphere. Error bars represent the standard error of the mean for three replicates.

[45] and promote the reaction efficiency of Na-OL-1 with $\mathrm{H}_{2} \mathrm{O}_{2}$ and $\mathrm{O}_{2}$ (reaction 1-4), resulting in the high activity for $\mathrm{MB}$ decolorization in $\mathrm{Na}-\mathrm{OL}-1 / \mathrm{H}_{2} \mathrm{O}_{2}$ system.

\section{Conclusion}

The Na-OL-1 was a well-crystallized octahedral layer (OL) structure with several different phases, including $\beta-\mathrm{MnOOH}, \alpha-\mathrm{MnOOH}$ and $\gamma-\mathrm{Mn}_{3} \mathrm{O}_{4}$. The catalyst exhibited high activity for the decolorization and degradation of methylene blue in the presence of $\mathrm{H}_{2} \mathrm{O}_{2}$ at neutral $\mathrm{pH}$. The tested $\mathrm{MB}$ was completely decolorized in Na-OL-1 suspension by the fraction dosing of $\mathrm{H}_{2} \mathrm{O}_{2} \cdot{ }^{1} \mathrm{O}_{2}$ and $\mathrm{O}_{2}{ }^{\bullet-}$ were the main reactive oxygen species in the reaction by the studies of electron spin resonance and the effect of radical scavengers. It was found that $\mathrm{H}_{2} \mathrm{O}_{2}$ was quickly decomposed into oxygen and ROS in Na-OL-1. Both pathways of $\mathrm{H}_{2} \mathrm{O}_{2}$ decomposition were proposed based on different experimental results, indicating that multivalent manganese oxides in Na-OL-1 enhanced the interfacial electron transfer, leading to its high reactivity.

\section{Acknowledgments}

This work was supported by the National Natural Science Foundation of China (Nos. 50908223, 50921064) and the National 973 Project of China (Grant No. 2010CB933600).

\section{Appendix A. Supplementary data}

Supplementary data associated with this article can be found, in the online version, at doi:10.1016/j.jhazmat.2011.03.120.

\section{References}

[1] M. Rafatullah, O. Sulaiman, R. Hashim, A. Ahmad, Adsorption of methylene blue on low-cost adsorbents: a review, J. Hazard. Mater. 177 (2010) 70-80.

[2] F. Haber, J. Weiss, The catalytic decomposition of hydrogen peroxide by iron salts, Proc. R. Soc. Lond., Ser. A 147 (1934) 332-351.

[3] D.L. Sedlak, A.W. Andren, Oxidation of chlorobenzene with Fenton's reagent, Environ. Sci. Technol. 25 (1991) 777-782.

[4] J.J. Pignatello, Dark and photoassisted $\mathrm{Fe}^{3+}$-catalyzed degradation of chlorophenoxy herbicides by hydrogen peroxide, Environ. Sci. Technol. 26 (1992) 944-951.

[5] S. Parra, I. Guasaquillo, O. Enea, E. Mielczarski, J. Mielczarki, P. Albers, L. Kiwi-Minsker, J. Kiwi, Abatement of an azo dye on structured C-Nafion/Fe-ion surfaces by photo-Fenton reactions leading to carboxylate intermediates with a remarkable biodegradability increase of the treated solution, J. Phys. Chem. B 107 (2003) 7026-7035.

[6] H. Lim, J. Lee, S. Jin, J. Kim, J. Yoon, T. Hyeon, Highly active heterogeneous Fenton catalyst using iron oxide nanoparticles immobilized in alumina coated mesoporous silica, Chem. Commun. 4 (2006) 463-465.
[7] J. He, W. Ma, J. He, J. Zhao, J.C. Yu, Photooxidation of azo dye in aqueous dispersions of $\mathrm{H}_{2} \mathrm{O}_{2} / \alpha-\mathrm{FeOOH}$, Appl. Catal. B: Environ. 39 (2002) 211-220.

[8] R.C.C. Costa, M.F.F. Lelis, L.C.A. Oliveira, J.D. Fabris, J.D. Ardisson, R.R.V.A. Rios, C.N. Silva, R.M. Lago, Novel active heterogeneous Fenton system based on $\mathrm{Fe}_{3-x} \mathrm{M}_{x} \mathrm{O}_{4}$ (Fe, $\left.\mathrm{Co}, \mathrm{Mn}, \mathrm{Ni}\right)$ : the role of $\mathrm{M}^{2+}$ species on the reactivity towards $\mathrm{H}_{2} \mathrm{O}_{2}$ reactions, J. Hazard. Mater. 129 (2006) 171-178.

[9] F. Magalhães, M.C. Pereira, S.E.C. Botrel, J.D. Fabris, W.A. Macedo, R. Mendonça, R.M. Lago, L.C.A. Oliveira, $\mathrm{Cr}$-containing magnetites $\mathrm{Fe}_{3-x} \mathrm{Cr}_{x} \mathrm{O}_{4}$ : the role of $\mathrm{Cr}^{3+}$ and $\mathrm{Fe}^{2+}$ on the stability and reactivity towards $\mathrm{H}_{2} \mathrm{O}_{2}$ reactions, Appl. Catal. A: Gen. 332 (2007) 115-123.

[10] L.C.A. Oliveira, T.C. Ramalho, E.F. Souza, M. Gonçalves, D.Q.L. Oliveira, M.C Pereira, J.D. Fabris, Catalytic properties of goethite prepared in the presence of $\mathrm{Nb}$ on oxidation reactions in water: computational and experimental studies, Appl. Catal. B: Environ. 83 (2008) 169-176.

[11] A.C. Silva, D.Q.L. Oliveira, L.C.A. Oliveira, A.S. Anastácio, T.C. Ramalho, J.H. Lopes, H.W.P. Carvalho, C.E.R. Torres, Nb-containing hematites $\mathrm{Fe}_{2-x} \mathrm{Nb}_{x} \mathrm{O}_{3}$ : the role of $\mathrm{Nb}^{5+}$ on the reactivity in presence of the $\mathrm{H}_{2} \mathrm{O}_{2}$ or ultraviolet light, Appl. Catal. A: Gen. 357 (2009) 79-84.

[12] S. Yang, H. He, D. Wu, D. Chen, X. Liang, Z. Qin, M. Fan, J. Zhu, P. Yuan, Decolorization of methylene blue by heterogeneous Fenton reaction using $\mathrm{Fe}_{3-x} \mathrm{Ti}_{x} \mathrm{O}_{4}$ $(0 \leq x \leq 0.78)$ at neutral pH values, Appl. Catal. B: Environ. 89 (2009) 527-535.

[13] M.B. Kasiri, H. Aleboyeh, A. Aleboyeh, Degradation of Acid Blue 74 using Fe-ZSM-5 zeolite as a heterogeneous photo-Fenton catalyst, Appl. Catal. B: Environ. 84 (2008) 9-15.

[14] B. Iurascu, I. Siminiceanu, D. Vione, M.A. Vicente, A. Gil, Phenol degradation in water through a heterogeneous photo-Fenton process catalyzed by Fe-treated laponite, Water Res. 43 (2009) 1313-1322.

[15] Q. Chen, P. Wu, Y. Li, N. Zhu, Z. Dang, Heterogeneous photo-Fenton photodegradation of reactive brilliant orange X-GN over iron-pillared montmorillonite under visible irradiation, J. Hazard. Mater. 168 (2009) 901-908.

[16] J.H. Ramirez, F.J. Maldonado-Hódar, A.F. Pérez-Cadenas, C. Moreno-Castilla, C.A. Costa, L.M. Madeira, Azo-dye Orange II degradation by heterogeneous Fentonlike reaction using carbon-Fe catalysts, Appl. Catal. B: Environ. 75 (2007) 312-323.

[17] F. Duarte, F.J. Maldonado-Hódar, A.F. Pérez-Cadenas, L.M. Madeira, Fenton-like degradation of azo-dye Orange II catalyzed by transition metals on carbon aerogels, Appl. Catal. B: Environ. 85 (2009) 139-147.

[18] Z. Yang, Y. Zhang, W. Zhang, X. Wang, Y. Qian, X. Wen, S. Yang, Nanorods of manganese oxides: synthesis, characterization and catalytic application, J. Sol. State Chem. 179 (2006) 679-684.

[19] W. Zhang, Z. Yang, X. Wang, Y. Zhang, X. Wen, S. Yang, Large-scale synthesis of $\beta-\mathrm{MnO}_{2}$ nanorods and their rapid and efficient catalytic oxidation of methylene blue dye, Catal. Commun. 7 (2006) 408-412.

[20] Y. Yin, W. Xu, R. DeGuzman, S.L. Suib, C.L. O'Young, Studies of stability and reactivity of synthetic cryptomelane-like manganese oxide octahedral molecular sieves, Inorg. Chem. 33 (1994) 4384-4389.

[21] S.L. Suib, Structure, porosity, and redox in porous manganese oxide octahedra layer and molecular sieve materials, J. Mater. Chem. 18 (2008) 1623-1631.

[22] Q. Feng, H. Kanoh, Y. Miyai, K. Ooi, Hydrothermal synthesis of lithium and sodium manganese oxides and their metal ion extraction/insertion reactions, Chem. Mater. 7 (1995) 1226-1232.

[23] A.L. Cabrer, M.B. Maple, G. Arrhenius, Catalysis of carbon monoxide methanation by deep sea manganate minerals, Appl. Catal. 64 (1990) 309-320.

[24] S. Ching, D.J. Petrovay, M.L. Jorgensen, S.L. Suib, Sol-gel synthesis of layered birnessite-type manganese oxides, Inorg. Chem. 36 (1997) 883-890.

[25] L. Espinal, S.L. Suib, J.F. Rusling, Electrochemical catalysis of styrene epoxidation with films of $\mathrm{MnO}_{2}$ nanoparticles and $\mathrm{H}_{2} \mathrm{O}_{2}$, J. Am. Chem. Soc. 126 (2004) 7676-7682.

[26] Y.F. Han, F.X. Chen, K. Ramesh, Z.Y. Zhong, E. Widjaja, L.W. Chen, Preparation of nanosized $\mathrm{Mn}_{3} \mathrm{O}_{4} / \mathrm{SBA}-15$ catalyst for complete oxidation of low concentration EtOH in aqueous solution with $\mathrm{H}_{2} \mathrm{O}_{2}$, Appl. Catal. B: Environ. 76(2007)227-234.

[27] R.J. Watts, J. Sarasa, F.J. Loge, A.L. Teel, Oxidative and reductive pathways in manganese-catalyzed Fenton's reactions, J. Environ. Eng. 131 (2005) 158-164.

[28] S.H. Do, B. Batchelor, H.K. Lee, S.H. Kong, Hydrogen peroxide decomposition on manganese oxide (pyrolusite): kinetics, intermediates, and mechanism, Chemosphere 75 (2009) 8-12.

[29] O Furman, D.F. Laine, A. Blumenfeld, A.L. Teel, K. Shimizu, I.F. Cheng. R.J. Watts, Enhanced reactivity of superoxide in water-solid matrices, Environ. Sci. Technol. 43 (2009) 1528-1533.

[30] J. Luo, S.L. Suib, Preparative parameters, magnesium effects, and anion effects in the crystallization of birnessites, J. Phys. Chem. B 101 (1997) 10403-10413.

[31] R. Chen, P. Zavalij, M.S. Whittingham, Hydrothermal synthesis and characterization of $\mathrm{K}_{x} \mathrm{MnO}_{2} \cdot y \mathrm{H}_{2} \mathrm{O}$, Chem. Mater. 8 (1996) 1275-1280.

[32] D. Yan, S. Chen, R.F. Zhuo, J.T. Chen, J.J. Feng, H.T. Feng, H.J. Li, Z.G. Wu, J. Wang, P.X. Yan, Nanoparticles and 3D sponge-like porous networks of manganese oxides and their microwave absorption properties, Nanotechnology 20 (2009) 105706-105716.

[33] T. Kohler, T. Armbruster, E. Libowitzky, Hydrogen bonding and Jahn-Teller distortion in Groutite, $\alpha-\mathrm{MnOOH}$, and manganite, $\gamma-\mathrm{MnOOH}$, and their relations to the manganese dioxides Ramsdellite and Pyrolusite, J. Sol. State Chem. 133 (1997) 486-500.

[34] J. Luo, A. Huang, S.H. Park, S.L. Suib, C.L. O’Young, Crystallization of sodiumbirnessite and accompanied phase transformation, Chem. Mater. 10 (1998) 1561-1568.

[35] N.N. Fathima, R. Aravindhan, J.R. Rao, B.U. Nair, Dye house wastewater treatment through advanced oxidation process using $\mathrm{Cu}$-exchanged 
Y zeolite: a heterogeneous catalytic approach, Chemosphere 70 (2008) 1146-1151.

[36] K. Imamura, E. Ikeda, T. Nagayasu, T. Sakiyama, K. Nakanishi, Adsorption behavior of methylene blue and its congeners on a stainless steel surface, J. Colloid Interface Sci. 245 (2002) 50-57.

[37] Y. Yan, M. Zhang, K. Gong, L. Su, Z. Guo, L. Mao, Adsorption of methylene blue dye onto carbon nanotubes: a route to an electrochemically functional nanostructure and its layer-by-layer assembled nanocomposite, Chem. Mater. 17 (2005) 3457-3463.

[38] D. Gutiérrez-Tauste, X. Domènech, N. Casañ-Pastor, J.A. Ayllón, Characterization of methylene blue/ $\mathrm{TiO}_{2}$ hybrid thin films prepared by the liquid phase deposition (LPD) method: application for fabrication of light-activated colorimetric oxygen indicators, J. Photochem. Photobiol. A: Chem. 187 (2007) 45-52.

[39] H. Ma, Q. Zhuo, B. Wang, Electro-catalytic degradation of methylene blue wastewater assisted by $\mathrm{Fe}_{2} \mathrm{O}_{3}$-modified kaolin, Chem. Eng. J. 155 (2009) 248-253.

[40] Q. Zhuo, H. Ma, B. Wang, F. Fan, Degradation of methylene blue: optimization of operating condition through a statistical technique and environmen- tal estimate of the treated wastewater, J. Hazard. Mater. 153 (2008) 44-51.

[41] M. Yin, Z. Li, J. Kou, Z. Zou, Mechanism investigation of visible light-induced degradation in a heterogeneous $\mathrm{TiO}_{2} /$ eosin $\mathrm{Y} /$ rhodamine B system, Environ. Sci. Technol. 43 (2009) 8361-8366.

[42] Y. Chen, C. Hu, J.H. Qu, M. Yang, Photodegradation of tetracycline and formation of reactive oxygen species in aqueous tetracycline solution under simulated sunlight irradiation, J. Photochem. Photobiol. A: Chem. 197 (2008) 81-87.

[43] Y.N. Lee, R.M. Lago, J.L.G. Fierro, J. González, Hydrogen peroxide decomposition over $\mathrm{Ln}_{1-x} \mathrm{~A}_{x} \mathrm{MnO}_{3}$ ( $\mathrm{Ln}=\mathrm{La}$ or $\mathrm{Nd}$ and $\mathrm{A}=\mathrm{K}$ or $\mathrm{Sr}$ ) perovskites, Appl. Catal. A: Gen. 215 (2001) 245-256.

[44] D. Zhang, R. Qiu, L. Song, B. Eric, Y. Mo, X. Huang, Role of oxygen active species in the photocatalytic degradation of phenol using polymer sensitized $\mathrm{TiO}_{2}$ under visible light irradiation, J. Hazard. Mater. 163 (2009) 843-847.

[45] L. Yang, C. Hu, Y.L. Nie, J.H. Qu, Catalytic ozonation of selected pharmaceuticals over mesoporous alumina-supported manganese oxide, Environ. Sci. Technol. 43 (2009) 2525-2529. 